\title{
Investigating intertextuality and interdiscursivity in evaluation: The case of conceptual blending
}

Stella Bullo

(Received 30 November 2015 - Revised 17 January 2017 - Accepted 07 February 2017)

\section{Introduction}

This paper investigates the meaning making practices of participants in a focus group engaged in a discussion of intertextual advertisements. It explores how the participants create meaning through intertextual and interdiscursive references and in so doing evaluate the advertisements under discussion.

The motivation for this study springs from an interest in sense making language in the reception and evaluation of intertextual media texts (Bullo, 2014). Previous studies in the field (ibid), have identified intertextuality as a device deployed during meaning making to support evaluative positioning (Bullo, 2014). In this work, I explore such practice further and argue that for a full account of sense making it is necessary to examine the notion of intertextuality beyond its traditional conceptualisation as a feature of texts (e.g. Kristeva, 1986) and investigate the inner cognitive mechanisms that take place in the audience during their language production in reception. By co-deploying Fauconnier and Turner's (2002) generic model of conceptual blending theory with Martin and White's (2005) appraisal theory framework for the analysis of evaluative language, this work argues that intertextuality needs to be conceptualised as a process of conceptual integration during sense making. The aim of this paper is hence to investigate intertextuality and interdiscursivity as linguistic evidence of the participants' cognitive operation in sense making during the evaluative process. 
The article starts by addressing the notion of intertextuality and interdiscursivity and their relationship to sense making. This will be followed by an introduction to conceptual blending theory (Facounnier and Turner 2002) as the theoretical basis for further analysis of intertextuality. An examination of the concept of attitude, which I discuss in its linguistic realisation as evaluative language through the lens of appraisal theory (Martin and White, 2005) will follow. Four instances of intertextuality and interdiscursivity identified in linguistic data from the focus group's discussion are then analysed as illustration of the main argument.

\section{Intertextuality}

Intertextuality is a fluid concept which has been studied from a multiplicity of fields in scholarly work for over 30 years. It became popular in the late 1960s with literary theorist Julia Kristeva who, building on Bakhtin's work, coined to term to refer to the structural relations between two or more texts. Kristeva, proposed that "each text is an intersection of texts where at least one other text can be read" (1986, p.37). Employing Bakhtin's (1981) concept of dialogism suggesting that "the meaning of an utterance is always half someone else's" (p. 293), Kristeva observes that a text is comprehensible through "a mosaic of quotations" (ibid) and claims that a text has no single meaning which can ultimately be relied upon in its transmission. Within the field of critical linguistics, intertextuality has been systematically studied as the structural integration of one text into another through a "rewording of the original", a notion that Fairclough calls "manifest intertextuality" (1992, p. 104). A further notion proposed by Fairclough is that of "constitutive intertextuality", or "interdiscursivity" (ibid). This relates to how current texts draw upon conventions of text constitutions such as "genre...discourse...style", which they "reaccentuate, rework and mix in various ways" (Fairclough, 1992, p. 103) ${ }^{\mathrm{i}}$. Interdiscursivity is thus seen as "the transfer of 
particular linguistic features that are typical of one discourse (or genre) to texts that represent another one" (Koller, 2010, p. 370). For the purposes of argument flow, I will discuss both intertextuality and interdiscursivity in the reminding of section only under the generic heading of intertextuality, as the argument is applicable to both concepts.

The traditional view of intertextuality as being a property of texts has been challenged by studies in the field of social semiotics and reception studies which pose the need to shift the emphasis from text analysis to the social process of reception of intertextuality. Hodge and Kress (1988) suggest that texts gain meaning from an intertextual relationship with other texts by virtue of the reader's active retracing of the path already constructed in previous texts. Similarly, Meinhof and Smith (2000) discuss that intertextuality is defined by the "relationship between text and audience" (p.11), hinting at a more complex conception of intertextuality as "the interaction between texts, producers of text and their readers' lifeworlds" (p.3). This emphasis on the receiver also includes the social and cultural references that the audience brings to the engagement with the text and meaning making process. Meinhof and van Leeuwen refer to the latter as intertextual readings (2000). Despite the openness of texts, they warn, such readings are made in "response to texts" and organised in patterns of meaning making that are subject to "knowledge, attitudes and beliefs of viewers" (Meinhof and van Leeuwen, 2000, p. 62).

The views above hint at the active role of the audience in decoding and constructing meaning from media texts and hence address the need for the examination of the social processes intervening in sense making of intertextuality. However, the internal conceptual mechanisms taking place in the audience during sense making and intertextual meanings attached to such sense making are left unaccounted for. An interesting view put forward by van Heerden (2009) in an examination of theological intertexts through the lens of conceptual integration (Fauconnier and Turner, 2002) is that the construction of intertextual meaning is reliant on 
encyclopedic knowledge and embodied experience of previous texts. This observation allows for the notion of meaning making to reside in the audience rather than in the text and calls for an exploration not only of outer text influences but also of inner cognitive processes that take place in the audience when intertextuality is at interplay in order to get a full account of sense making. This is particularly necessary when investigating intertextuality given its reliance on the readers' encyclopaedic knowledge and experience of previous texts or text constitution conventions. Further to this, if we are to consider pre-existing attitudes to previous texts travelling to the reception of the new text, as suggested by Meinhof and van Leeuwen (2000) discussed above, then it is necessary to explore the role of attitudinal disposition in sense making.

The above discussion allows for the view that intertextuality and interdiscursivity can be seen as evidence of conceptual integration actively established by the participants in interaction through their decoding of the advertisements, as this work pursues. By this I mean that during the sense making process, the adverts under discussion by the focus group participants are checked against the audience's knowledge structure which includes knowledge of the genre of advertising and awareness of the intertexts presented in the adverts. Such knowledge structures are containers of attitudinal dispositions that are activated through the process of sense making and evidenced through evaluative instances of language in interaction. Thus, the evaluation of the advertisement appears as an emergent structure of the blending process that materialises as a result of the participants' conceptualization in language.

The next section outlines conceptual blending theory and appraisal theory as proposed approaches for the investigation of intertextuality and interdiscursivity in sense making language. 


\section{Investigating intertextuality an interdiscursivity in sense making: Towards a theoretical framework}

\subsection{Conceptual Blending Theory (CBT)}

Fauconnier and Turner's (2002) theory of cognition conceives the existence of a subconscious process to meaning making and is concerned with "the dynamic aspects of meaning construction" (Evans \& Green, 2006, p. 400). This process entails the ability to combine, or blend, elements from diverse scenarios or mental spaces with shared schematic structures, prompting parallels between them, and to form a new conceptual model for use in problem solving.

A fundamental concept of the theory is that of mental spaces, or "conceptual packets constructed as we think or talk, for the purposes of local understanding and action" (Fauconnier \& Turner, 2002, p. 40). Background knowledge provides schematic structures, which are connected to mental spaces. Such schematic configurations are structured by cognitive frames that contain a variety of "background assumptions" (Hart, 2010, p.116). Mental spaces "join to form complex networks during cognitive activities such as the production and comprehension of texts" (Semino, 2012, p. 117). Diverse mental spaces dealing with different subjects can be 'blended' or merged. The basic blending network, proposed by Fauconnier and Turner, is composed of four mental spaces: two input spaces, one generic space, and the blended space. Input spaces constitute what Hart (2010) calls the 'situation spaces'. Each input space has a counterpart in the other input space which are linked by relations or cross-space mappings. Such relations or, mappings, are known as 'vital relations' and can fall under analogy, category, identity, intentionality role, and time and space (Fauconnier and Turner 2002, p. 89-111). Input spaces are informed by domains which consist of schemata, representative of socio-cultural experience, stored in long-term memory (Evans and Green, 2006). There is also a generic space, which is at a higher level of 
abstraction and contains the conceptual structure that both input spaces share. Finally, there is a blended space where the elements from both input spaces are joined together. The blend thus inherits partial structure from both the input spaces, as well as from the generic space, and constitutes integrated conceptualisation of a specific notion from which a new emergent structure arises. This emergent structure, despite inheriting structure, knowledge and assumptions from the input spaces, is still unique and novel to the blend. In other words, it "is a product of blending operations" (Hart, 2010, p.116).

Hart makes an observation that only structure from cognitive frames "which is relevant to the text-producer's intention in constructing the blend... gets projected into the blended space" (2010, p. 117). He calls this 'selective projection' and argues that this selective projection, which happens at the elaboration stage of the blend, is an indicator (or, facilitator) of ideological positioning "whereby text-producers may choose to recruit particular structure in order to promote a certain construal of reality" (ibid). Hence, selective projection can be seen to partly determine the expression of attitude towards a stimulus and the inclination to view it as normal or deviant, positive or negative. This is further hinted at by Fauconnier and Turner (1998), who point out that "blended spaces are sites for central cognitive work: reasoning..., drawing inferences..., and developing emotions" (p.4). It is the latter aspect, the emotional component arising at the elaboration stage of a blended space, which may work as an indication of an attitudinal disposition manifested in evaluative lexis on which this work centres. I will discuss the notion of attitude and evaluation in the following section.

\subsection{Attitude}

Attitude research represents a long-standing tradition within social psychology. Within the discipline, the structural definition of attitude tends to relate to an object or stimulus towards 
which to direct an evaluation, the act of evaluating, and the evaluating agent (Ajzen, 2001; Eagly \& Chaiken, 1993; Gaskell, 2001; Petty et al., 1997). They are a social construct, rather than an individual phenomenon (van Dijk, 1998), and have an idiosyncratic nature (Augoustinos et al., 2006). Pratkanis and Greenwald, in their socio-cognitive model of attitudes, add to the above the notion of "a knowledge structure supporting the evaluation" (1989, p. 249). Within linguistics, Hunston and Thompson (2003, p. 5) suggest that "evaluation is the broad cover term for the expression of the speaker or writer's attitude or their stance towards, viewpoint on, or feelings about the entities or propositions that she or he is talking about". I approach attitude as evaluative responses, with either positive or negative valence, towards a stimulus contained within knowledge structures (Bullo, 2014). Such responses are manifested at text level though a selection of evaluative lexis.

One linguistic approach to the study of evaluative language is provided by the appraisal typology (Martin and White, 2005) which offers useful tools for text parsing that allow for a structured text analysis of evaluative language. Set within the systemic functional linguistics (SFL) tradition, the attitude subsystem of the appraisal framework provides a useful set of tools for the study of evaluative language focussing on the selection of lexical choices, expressing positive or negative disposition in such a way that those choices are seen to "reflect and reinforce the ideological values of the culture" (Thomson, 2004, p. 76) ${ }^{\mathrm{ii}}$. The main subsystems within the attitude system of appraisal theory which categorise lexical selections for the evaluation of objects and entities are as follows: (1) affect values are concerned with feelings and emotions towards an entity by an emoter and can be either manifestations of the speaker's own feelings (i.e. authorial affect) or attributed to an external entity by the speaker (non-authorial affect); (2) appreciation, concerned with evaluating objects and the attributes or qualities of entities, that is the compositional or aesthetic features of the entity under scrutiny; (3) judgement is typically concerned with the evaluation based 
on moral or ethical values. The appraisal can be explicitly inscribed through lexical items that overly indicate the evaluative disposition - e.g., it holds very nicely. It may also be implicitly evoked through a variety of features and functions of language where the full utterance must be considered as realising the evaluative instance, rather than the lexical item in isolation e.g., it doesn't do it for me. Let me illustrate the categories with inscribed appraisal examples from the focus group data used for this study, where participants were asked to discuss printed advertisements: (a) makes me sick: shows an evaluative disposition based on an authorial emotional reaction, i.e. affect; (b) holds nicely...balanced...harmonious: evaluation based on the compositional and aesthetic features of the entity being appraised, i.e. appreciation; (c) it's very elitist: the evaluation is concerned with a disposition based on moral or ethical grounds, i.e. Judgement.

All in all, this paper sets out to show that the co-deployment of the appraisal framework tools for a text level analysis of attitude contained within knowledge structures informing the blend's input spaces can allow for a rounded account of the role of intertextuality and interdiscursivity in meaning making. The next section provides a practical application by analysing intertextual and interdiscursive references in sense making data co-deploying the frameworks outlined above.

\section{Application to sense making data}

In order to illustrate the concepts developed so far, extracts of data from focus group discussions of advertisements containing intertextual references to works of art have been selected. The adverts presented in this paper were discussed during the same conversation where the theme of art was the background to the discussion due to the advertisements intertextual references. All the participants in the focus groups were professional British, 
aged between 35 and 40. They all shared an interest in art which they pursued as a hobby. Two of them were art producers themselves as a hobbies (textiles and painting) and three of them had an interest in art history and made it clear that visited art galleries and museums regularly.

Two specific examples of intertextuality and of interdiscursivity used by the participants during the discussion of the adverts are analysed. The data was originally collected and used in a larger study on the discourse of advertising reception (Bullo, 2014). As this paper focuses on the audience's responses to particular advertisements, rather than the advertisements as texts, the advertisements discussed have not been included in this work ${ }^{\text {iii }}$. However, an extensive description of the adverts is provided, where necessary, for the understanding of the analysed stretches of conversation in the next section. Should the reader be interested in pursuing a further investigation of the advertisements discussed, they can be found in Bullo (2014, pages 52; 56 and 59).

\subsection{Intertextuality as evidence of CBT}

Extract 1 - Holland advert: it's enigmatic like the Mona Lisa

The above is a line from a stretch of conversation during the discussion of an advertisement produced by the Holland Tourist Board featuring an intertextual reference to the painting by Vermeer, The Girl with the Pearl Earring (Bullo, 2014, p. 52). The advert presents a fair skinned woman wearing an orange headscarf, a brown garment and a pearl earring. She is pictured against a light background and is looking into a mirror, projecting what appears to be a version of Vermeer's painting onto her own image, gazing at the onlooker. The only copy the advert has is the internet address 'www.holland.com'. Despite the connection to Vermeer's painting being made by the focus groups participants immediately (e.g. it tries to 
re-create the Vermeer's painting), the advert was compared to the Mona Lisa painting as it was appraised. The evaluation of the advert overall is negative on the basis that it is unclear what its purpose is and it is centred on lexical selections related to its composition, the most prominent one being enigmatic followed by the link to the Mona Lisa painting. The textual constitution of the advert provided a frame structure consisting of a woman gazing at the audience and an unclear message being communicated. Such frame structure triggered intertextual references to a work of art with a similar structure.

The sense making process can be inferred as follows. As graphically represented in figure one, the first input space is formed by the advert for Holland (indicated by the copy www.holland.com) featuring a woman gazing at the audience. The lack of a clear communicative purpose of the advert informs this input space. Leonardo da Vinci's Mona Lisa painting featuring Mona Lisa smiling gently constitutes the second input space. The connection to art as background to the conversation and the knowledge to the widespread notion of the Mona Lisa painting, and in particular her smile, being 'enigmatic' inform input space 2. Both input spaces have the conceptual structure of the visual representation of a woman in common (generic space). 
Input space 1:

Advert for Holland with copy 'www.holland.com'.

Character gazing at audience.

Background frame:

The advert's purpose is unclear.
Generic space:

Visual representation of a

woman with a gesture

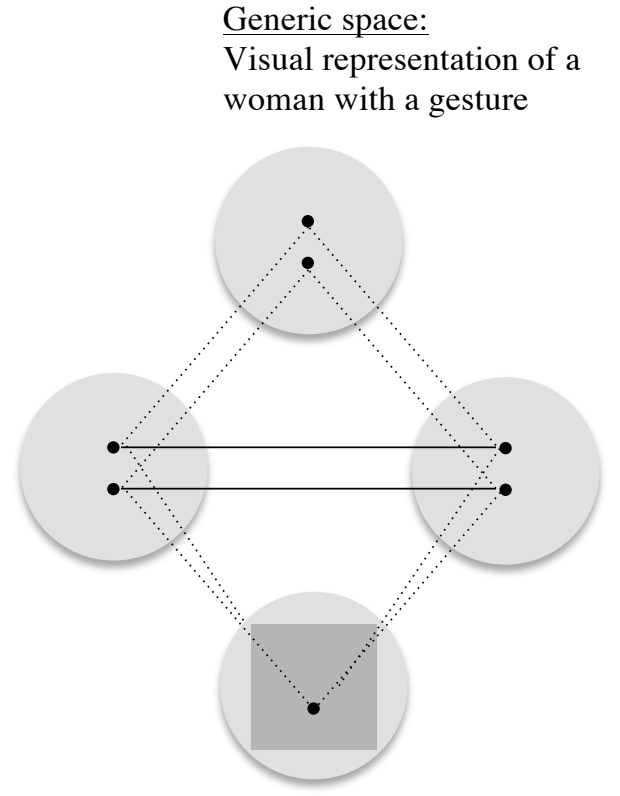

Emergent structure:

The advert is enigmatic

Negative appraisal of the ad under the category of appreciation.
Input space 2:

The Mona Lisa painting.

Mona Lisa smiling.

\section{Background frame:}

Knowledge of Mona

Lisa's smile considered enigmatic.

Connection to art in the conversation.

Figure 1: Extract 1 blended space

This commonality in structure completes the blend by mapping the counterparts in the input spaces, i.e. the woman in the advertisement and Mona Lisa. These elements are modified "imaginatively" in the elaboration stage (Fauconnier \& Turner, 2002, p. 45) and blend in an emergent structure containing the appraisal. The advert is appraised as enigmatic, falling under the appraisal category of appreciation: the evaluation is based on the compositional or aesthetic features of the images whereby the attribute of mystery residing in the participants' stock of knowledge in respect to Mona Lisa is transferred onto the advert.

The comparative like in the utterance functions as an indicator of the reference and the analogy relation between the two texts constituting the blend's input spaces. In this process, the comparative also evidences the classification and allocation of the unfamiliar stimulus (the advertisement, which is not fully made sense of) into a familiar notion (Mona Lisa painting). It is worth noting that the lexical item enigmatic does not carry a negative valence in itself and could be considered ambivalent. However, the context for the appraisal of this 
advert and the co-text for this utterance indicate a negative disposition towards the advertisement based on the participants' lack of understanding of its purpose.

Extract 2 - Ikea advert: I thought well Calendar Girls, it's saying you are a strong woman

The extract above is a stretch of conversation during the discussion of an IKEA advertisement (full image found in Bullo, 2014, p. 59). The advert features a mature nude woman sitting cross-legged on an outdoor chair and in an outdoor setting. The woman is only wearing sandals, a hat, sunglasses, and a pearl necklace. She appears to be smiling while holding a cup and saucer in her hand. She is centred in the foreground of the image and behind her there is a row of prefabricated white wooden cottages that recede into the background. The cottage immediately behind the woman features a mural of half of Botticelli's 'Birth of Venus' painting in shades of yellow and orange. The copy at the bottom right of the page reads 'It's your world [IKEA logo] live better'.

The discussion of this advert centres around the nude female figure and the advert's copy that is seen to be addressing the woman directly and advising her that she is free to decorate her home as she likes. The copy is thus seen as empowering the woman to choose her home furnishing and decoration style as well as to live freely. By means of an intertextual reference to the film Calendar Girls ${ }^{\mathrm{iv}}$, the woman is appraised as strong by the focus groups participants. It is interesting that, at this point, no mention was made to the Boticelli's painting in the background. Rather than the connection to art framing the sense making, it is the film's plot that interacts in the blending process. In the film storyline, one of the characters goes on a mission to convince other women in her local circle to pose naked for a calendar in order to fund a memorial for her close friend's husband who had died. It is the 
perceived determination of the woman, represented otherwise in the early stages of the film that is selected by the informants to project onto the blend during sense making.

In the conceptual integration process, the generic space is constituted by the concept of nude female representation with a characterising trait. The first input space is formed by the represented mature woman with a relaxed attitude sitting naked in a garden chair in an outdoor space in the IKEA advert. The discussion about the perceived empowerment of the woman by IKEA through the advert's copy, along with the general knowledge of the flexibility of style that IKEA products offer, serve as background to the blend. The second input space contains the characters in the film Calendar Girls posing nude for a calendar in order to raise funds and the perceived strength of the characters. The input space is informed by background knowledge of the film's plot, characters and the actors involved. The blend inherits its main organising frame from the second input space. Hence, the most salient elements from both input spaces - namely the women, their perceived strength, their naked bodies being photographed - account for the emergent structure in the completion stage. This results in a blended space where the nude woman in the advert is attributed the characteristic perceived in the women in the film, i.e. strong. Figure 2 graphically represents this process below: 
Input space 1:

Mature nude woman with

a relaxed attitude in the

IKEA advert.

Background frame:

Advert copy 'it's your world'; message of empowerment.

Knowledge of IKEA's products and design offering flexibility of style.
Generic space:

Nude female representation

Characterising trait.

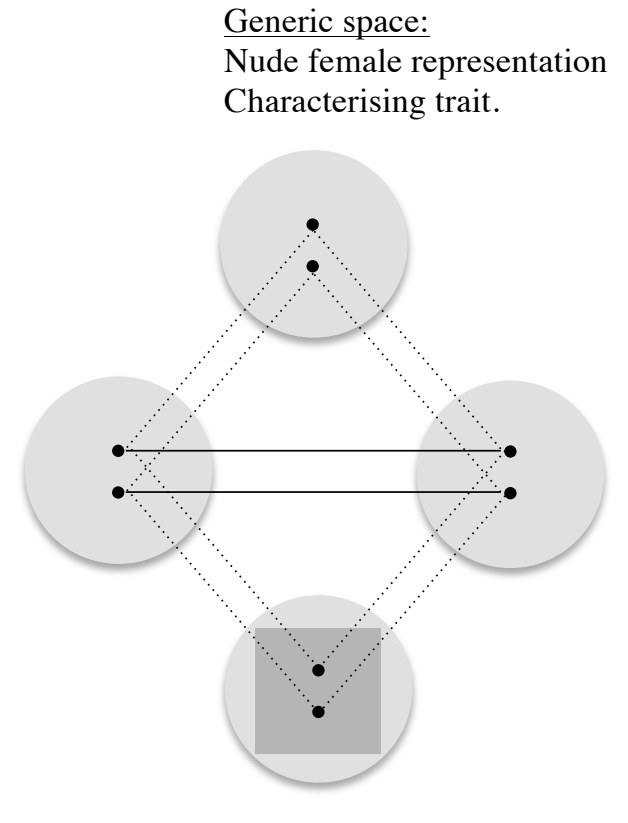

Emergent structure:

Nude woman in the advert is strong.

Positive appraisal of the woman under the category of judgement [tenacity].
Input space 2:

Mature female characters posing nude for a calendar in the Calendar Girls film.

Courage and

determination.

Background frame:

Film's plot.

Perception of the characters in the film as strong.

Knowledge of actors in the film.

Figure 2: Extract 2 blended space

The appraisal of judgement that arises from this blended space results from the selective projection of the represented character's nudity and the intertextual reference to nude women in the Calendar Girls film. It is worth clarifying that within the appraisal typology, judgement refers to evaluations based on ethical or moral grounds, as explained in section 3.2. This extract constitutes such a case given that the subsystem of judgement allows for the subcaterogisation of 'tenacity' which accounts for lexical selections based on the perceived dependability or disposition of the target of the appraisal (Martin and White, 2005).

\subsection{Interdiscursivity as evidence of CBT}


I discussed in section 2 that interdiscursivity concerns the relationships that a current text has with conventions of text constitution (genre or discourse), which are alluded to and reworked in various ways. In this case, it is worth pointing out that input spaces in the blend are not necessarily anchored to a physical entity (i.e. a visual text or painting) but rather to a concept (i.e. reference to a particular genre). The example below illustrates this point.

Extract 3 - Holland advert: and I thought her eyes were looking very longingly... and I thought about you know is it lusting is it desire I kind of thought definitely in her eyes they were very deep I saw the door handle next after her eyes and I thought there was a doorway there which she was either wanting the person to come with her to the doorway or is she leaving and I thought maybe there was a look of sadness in her eyes as well if she was leaving .

In the discussion of the Holland advert (described above in 4.1, extract 1; Bullo, 2014, p. 52), the speakers make sense of the advert within an alternative conceptual framework containing interdiscursive references to the genre of drama, which seems to structure the informants' interpretation and evaluation of the image. Once again, we can consider the interdiscursive reference as linguistic evidence of conceptual blending framing the appraisal.

I will explain how I see the blending process in this case. From the first input space, structured by the advertisement, the blend inherits the woman gazing at the onlooker, the setting (i.e., the door and door handle), and the costume. As I discussed earlier on, the theme of art was the background to the discussion of this advert. From the second input space, it inherits a frame structure with the compositional elements of the genre of drama (i.e., plot, character, theme, dialogue, music and spectacle ${ }^{\mathrm{v}}$ [Barranger, 2004]) and schematic knowledge of watching drama and audience involvement. The two input spaces share the 
structure represented in the generic space: a situation or succession of events having a dramatic progression or an emotional effect. ${ }^{\text {vi }}$ There seems to be a displacement between the woman (model) in the advertisement and the woman (actor) in a dramatic, and between the physical space of the advertisement (or the photography studio) and the physical space of the stage. The networks are linked by analogy of their structure. The informants also project themselves into the blend as the audience of the play. This is analogous to fictional dramatic scenes. The suspense created by a dramatic scene, when the audience is not clear as to how the drama will proceed, maps onto the uncertainty feelings of the audience who do not fully comprehend the advertisement and manifests as appraisal values of affect. Furthermore, negative feelings structured by the schematic knowledge of watching drama may also influence the interpretation of the image. Mental processes ${ }^{\mathrm{vii}}$ (e.g., think, feel) are used throughout, both to refer to the actor's assumed feelings and to the speakers' psychological experience when discussing the advertisement. The blend gives rise to an emergent structure projecting back to its counterparts in the input spaces. The blending process is illustrated in figure three below: 
Generic space:

Events with a dramatic progression and an emotional effect.

Input space 1: Advert: character and gaze, advert setting, costume; participants; Advert's copy with unclear message

Background frame: Art theme during the discussion and awareness of focus group discussion
Input space 2:

Drama genre: characters, setting, costumes; audience.

Plot and suspense

Background frame:

Schematic knowledge of watching drama and audience involvement.

Emergent structure:

Woman in the advert is character in a sad dramatic scene [appraisal of affect]. The participants are the audience of the sad dramatic scene [appraisal of affect].

Figure 3: Extract 3 blended space

In this process, the informants transferred their negative feelings towards the advertisement onto the represented character, from where the negative appraisal values of affect selected in the completion process arise.

Extract 4 - Holland advert: there are no cheese and tulips are there?

Within the discussion for the Holland advert outlined above, this stretch of conversation concentrates on the missing elements that would seem characteristic of an advertisement for Holland according to the participants' background knowledge and schematic structure of tourism advertising. The negative existential process ${ }^{\text {viii }}$ there are no and the question tag are 
there seem to work as checking mechanisms for validating shared views and illuminates the background knowledge at interplay in this stretch. Interdiscursive links to the genre of tourism advertising have an active role in this negative appraisal of the advert.

As represented in figure four below, from the first input space, the blend inherits a woman looking into a mirror, seemingly re-enacting a Dutch painting and an Internet address with the unclear message background information informing this space. From the second input space, structured by the interdiscursive reference to tourism advertising conventions, the blend inherits a schematic structure of tourism advertising containing conventional representational elements of the advertised location. The frame structure informing the second input space contains knowledge of traditional or characterising Dutch elements, such as cheese and tulips, and tourism advertising constitution conventions. The representation of Holland is the structure shared by both input spaces; the understanding of the scenario is completed by the juxtaposition of elements from the inputs in a disanalogy relation, giving rise to the blended space containing the appraisal. This is illustrated below: 
Generic space:

Country representation.

Input space 1: Advert: woman reenacting a Dutch painting and an internet address.

Background frame: The advert's purpose is unclear.

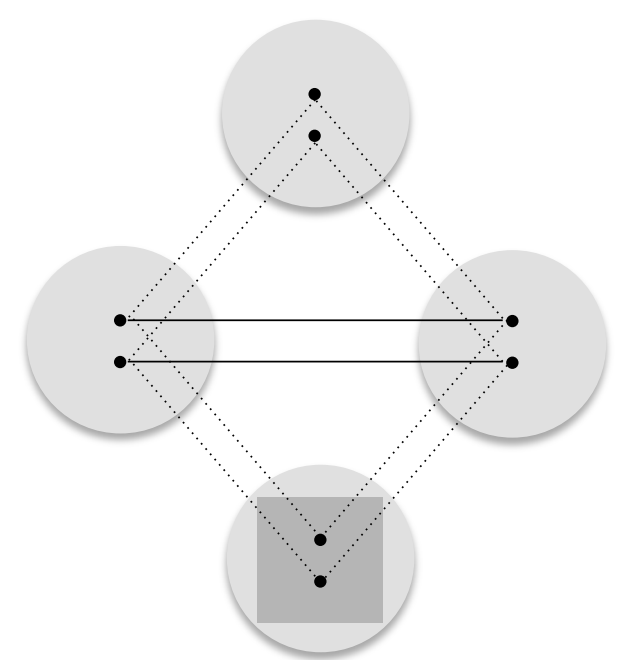

Emergent structure:

Inappropriate choice of representational elements for Holland. Incompetent production of the advert. The advert is appraised as ineffective (- invoked judgement).
Input space 2:

Genre of tourism

advertising genre featuring characterising features of the advertised place

Background frame:

Knowledge of advert constitution conventions. Knowledge of traditional Dutch elements

Figure 4: Extract 4 blended space

In this appraisal, the evaluation is not necessarily targeted at the advertisement. Rather, the absence of certain elements in the advertisement helps trigger schematic knowledge of expected elements in an advertisement for Holland thus rendering the advert incompetently produced. Within the appraisal typology of attitude, this turn can be categorized within the judgment subcategory of capacity, pointing at the human agent (advertisers) behind the text and towards the perceived in/ability to perform an activity (see Martin and White, 2005). Therefore, the completion process is a source of emergent negative appraisal, under the category of judgement, in the blended space.

\section{Discussion}


The data presented illustrated how conceptual integration underpins the participants' ability to make sense of the adverts and shows the multiple interpretations that interact in this process as manifested in intertextual choices in language use. The findings reveal a number of points of value to reception studies and language and cognition research.

This paper has illustrated how intertextual or interdiscursive construction of meaning relies on the audience's cognitive processing in aiding sense making. This paper has attempted to move away from the traditional view of intertextuality and interdiscursivity as the structural integration of a previous text into the current one and as the use of features that are typical of another discourse or genre and are alluded to in the text under consideration, respectively. Instead, it has argued that both phenomena, rather than being features of texts, can be seen as cognitive processes in the audience meaning making. By describing the cognitive processing behind intertextual and interdiscursive choices, the paper has conceptualised sense making as a dynamic process and highlighted the role of the receiver in actively deriving meaning and attitudinal position from texts. In so doing, it has shown that sense making is highly contextual and cannot be seen in isolation from the reservoir of knowledge informing text comprehension. It is in such knowledge that attitudinal positions rest and travel to then give rise to evaluative sense making when activated and integrated into the new stimulus through a conceptual process. This also indicates that sense making, in the context of this data discussion, has an inherently attitudinal component which is manifested in evaluative disposition towards a stimulus and that is realised in language through lexical selection of items carrying a positive or negative valence. Therefore, this hints at a conceptualisation of sense making in reception of media texts as the product of both social and conceptual processes and their interrelation. This is an interesting avenue worth pursuing further that would require exploring the social and cognitive processes involved in the sense making of a wider range of media texts. 
Further to this, the findings have also illustrated that intertextuality and interdiscursivity are processes reliant on the participants' social knowledge and their integration into conceptual structures and processes. These findings also point at a redefinition on intertextuality as a feature of texts and/or as a social process as historically been approached and enhances the need for an exploration focusing on the relation between the social and the cognitive processes interacting in intertextual meaning making.

The discussion of the data also indicates that, during the conceptual integration process, the participants' expression of attitude towards the advertising stimulus and the inclination to assign it positive or negative evaluation may have been determined by the selective projection of elements from the input spaces onto the blend. An instance of valence attributed to a particular feature of the text being referenced occurred in the Holland advertisement. In the discussion the gesture of the represented character in the Holland advert was projected onto the input space and mapped onto the Mona Lisa's smile in the second input space. Hence, the knowledge of valence attributed to the Mona Lisa's smile led to the attribution of the appraisal onto the advert's character in the emerging structure. This was picked up later in the discussion triggering interdiscursive references and knowledge and experience of the genre of drama that fed into the second blend leading to more negative appraisal on the advert, as discussed in section 4.2. The second blend, therefore, needs to be seen in relation to the first in order to fully contextualise the sense making. This seems to indicate a chain effect in the sense making processes, which is consistent with the nature of intertextuality and interdiscursivity, but also acknowledges the need for further investigation of conceptual blending in the data where more complex integration networks are deployed.

Of interest in the discussion of projective selection is also the underlying motivation for it. In other words, given that we are dealing with adverts, it is necessary to consider, albeit briefly, the text production process. The choices made by the text producers may have deliberately 
aimed at achieving a higher degree of the audience's personal and emotional involvement with the given stimulus, which may have had an impact on the selection of elements to be projected onto the input space. Forceville (2012) discusses the advantages of the deployment of multimodal devices in texts as follows: (a) they "communicate on a more directly emotional level than words do"; (b) they require "more cognitive effort on the part of the addressee"; (c) they "steer addressees into making inferences at their own responsibility and discretion, allowing for a degree of 'personalization' of a mass-medium message” (p.129). This is the case once again of the Holland advert where the gesture of the represented character lead to a high degree of the audience's emotional involvement with certain aspects or features of the adverts, as hinted by Forceville (2012), which may account for such conscious or unconscious selective projection. This is another aspect worth pursuing further that may need to consider both the production as well as the reception process in order to obtain a fuller account.

\section{Concluding remarks}

This paper has explored intertextuality and interdiscursivity in the reception of intertextual advertising. It has pointed out that, despite attempts to study intertextuality as a feature of language during text reception, the cognitive phenomena behind it as a sense making practice had been neglected. In so doing, this work has drawn on various paradigms ranging from literary theory and social semiotics to aspects from cognitive and functional approaches to linguistics in order to contextualise intertextuality and its relation to sense making and evaluation.

As it is the case with studies addressing various fields, depth had to be compromised. An important point worth discussing the deployment of the appraisal framework within cognitive 
language studies which is not a usual combination given the long-standing un-bridged tradition between the disciplines. Attitude, in the context of the appraisal framework, does not consider the cognitive dimension but relates to the discourse semantic resources at text level used to convey an evaluative stance. It is important to clarify that this work focuses the study of the relationship between attitude, intertextuality and conceptual integration. It has not been the intention of this work to expand the appraisal framework nor to challenge its theoretical underpinnings but rather to co-deploy its useful tools for text parsing in order allow for a structured text analysis and anchor the analysis of intertextuality. A debate into the plausibility and fruitfulness of on a theoretical integration of the disciplines would make an interesting contribution to the field. Furthermore, It is acknowledged that only a superficial analysis of appraisal is provided here. The main interest in this paper is to identify the main categories of evaluation by identification of the main appraisal categories (affect, appreciation, Judgement), rather than subcategories and their grammatical manifestation, as a way of anchoring the cognitive analysis. A further investigation deploying other appraisal systems and sub-categorisations using more data considering co-text and content would allow for a more in-depth and fruitful investigation of evaluative choices and the role of intertextuality in those choices.

Similarly, the paper draws on a simple model of conceptual blending without consideration of other types of integration networks. A further investigation of these areas covering less scope but further depth would enhance the findings of this study. For example, an investigation mapping the multiple media texts and genres interacting in sense making would allow for a more complex investigation of multiple types of integration networks interacting in intertextual meaning construction.

And finally, the findings shed light into another area that needs to be recognised in a study of the conceptual mechanisms involved in the reception process. This paper has deployed 
conceptual integration as a theory concerned with conceptualisation processes taking place in the individual's cognitive environment. However, by working with focus group data where a group of individuals are brought together on the basis of a shared common ground, is it necessary to consider the presumed dynamics of the situated group and its how this affects cognitive processes. In other words, conceptualisation needs not necessarily be seen as an individual process in this context as much as a joint process whereby cognitive resources are socially shared by individuals in a collaborative venture. This approach, known as distributed cognition (Hutchins, 1995) would explore the interaction between informants and focus "on the processes that take place in an extended cognitive system" (emphasis on original, Rogers, 2006, p. 731) of the focus group participants rather than concentrating exclusively on an individual's cognitive processes as the basic conceptual blending model deployed in this paper does. In this way, we would be able to account for the "coordinating mechanisms" used by the focus groups participants and the way "knowledge is shared and accessed" (ibid, p. 732) and meaning constructed in the intertextual sense making of advertisements.

All in all, this paper set out to investigate the relationship between intertextuality, cognition and sense making. In so doing, it has characterised sense making as a dynamic process that is reliant on the physical and socio-cultural knowledge and experiences of readers. It has also argued that intertextuality and interdiscursivity are linguistic evidence of dynamic processes in the readers' cognitive processing of texts rather than fixed properties of texts. Hence, investigating intertextual and interdiscursive texts from a cognitive perspective allows us insights into the inferential processes involved in the construction of meaning.

\section{References}


Augoustinos, M., Walker, I., \& Donaghue, N. (2006). Social cognition: An integrated introduction. London: Sage.

Ajzen, I. (2001). Nature and operation of attitudes. Annual Review of Psychology, 52, 27-58.

Bakhtin, M. (1981). The dialogic imagination: Four essays. ( $2^{\text {nd }}$ edition). C. Emerson, \& M. Holquist (trans.). In M. Holquist (Ed.). Austin: University of Texas Press.

Barranger, M. S. (2004). Understanding plays. Boston: Allyn and Bacon.

Bullo, S. (2014). Evaluation in advertising reception: A socio-cognitive study. Basingstoke: Palgrave Macmillan.

Eagly, A.H., \& Chaiken, S. (1993). The psychology of attitudes. Fort Worth: Harcourt, Brace, Jovanovich.

Evans, V., \& Green, M. (2006). Cognitive linguistics: An introduction. Edinburgh: Edinburgh University Press.

Fairclough, N. (1992). Discourse and social change. London: Polity Press.

Fauconnier G. \& Turner, M. (1998). Blending As A Central Process of Grammar. Mark Turner Home Page. Online. Available from http://www.cc.gatech.edu/classes/AY2013/cs7601_spring/papers/Fauconnier_Turner. pdf. [Accessed August 2015].

Fauconnier, G., \& Turner, M. (2002). The way we think: Conceptual blending and the mind's hidden complexities. New York: Basic Books.

Forceville, C. (2012). Creativity in pictorial and multimodal advertising metaphors. In R. Jones (Ed.), Discourse and Creativity. Harlow: Pearson/Longman. Pp. 113-132.

Gaskell, G. (2001). Attitudes, social representations and beyond. In K. Deaux, \& G. Philogène (Eds.), Representations of the social: Bridging theoretical traditions. Oxford: Blackwell. Pp. 228-241. 
Halliday, M.A.K., \& Matthiessen, C.M.I.M. (2004). An introduction to functional grammar. ( $3^{\text {rd }}$ edition). London: Arnold.

Hart, C. (2010). Critical discourse analysis and cognitive science: New perspectives on immigration discourse. Basingstoke: Palgrave Macmillan.

Hodge, R., \& Kress, G. (1988). Social semiotics. Cambridge: Polity Press.

Hunston, S., \& Thompson, G. (Eds.) (2003). Evaluation in text: Authorial stance and the construction of discourse. Oxford: Oxford University Press. Pp. 1-27.

Hutchins, E. (1995). Cognition in the wild. Cambridge, MA: MIT Press.

Koller, V . (2010). Lesbian nation: A case of multiple interdiscursivity. In R. de Cillia, H. Gruber, F. Menz, \& M. Krzyzanowski (Eds.), Discourse, politics, identity. Tübingen: Stauffenburg. Pp. 369-381.

Kristeva, J. (1986). Word, dialogue and novel. In Kristeva, J., \& Moi, T. (Ed.), The Kristeva reader. New York: Columbia University Press. Pp. 35-61.

Martin, J. R., \& White, P. R. R. (2005). The language of evaluation: Appraisal in English. Basingstoke: Palgrave Macmillan.

Meinhof, U., \& Smith, J. (Eds.) (2000), Intertextuality and the media: From genre to everyday life. Manchester: Manchester University Press. Pp. 1-17.

Meinhof , U., \& Van Leeuwen, T. (2000). Viewers' worlds: image, music, text and The Rock 'n' Roll Years. In U. Meinhof, \& J. Smith (Eds.), Intertextuality and the media: From genre to everyday life. Manchester: Manchester University Press. Pp. 61-75.

Petty, R., Wegener, D., \& Fabrigar, L. (1997). Attitudes and attitude change. Annual Review of Psychology, 48, 609-647.

Pratkanis, A.R., \& Greenwald, A.G. (1989). A socio-cognitive model of attitude structure and function. In L. Berkowitz (Ed.), Advances in experimental social psychology, 22. New York: Academic Press. Pp. 245-285. 
Rogers, Y. (2006). Distributed cognition and communication. In K. Brown (Ed.).

Encyclopedia of Language and Linguistics. (2nd edition.). Elsevier. Pp. 731-733.

Semino, E. (2012). Unrealistic scenarios, metaphorical blends and rhetorical strategies across genres. In B. Dancygier, J. Sanders, \& L. Vandelanotte. (Eds.), Textual choices in discourse: A view from cognitive linguistics. Amsterdam: John Benjamins. Pp. 111136.

Thompson, G. (2004). Introducing functional grammar. ( $2^{\text {nd }}$ edition). London: Arnold. van Dijk, T. A. (1998). Ideology: a multidisciplinary approach. London, Sage.

van Heerden, C. (2009). How religion might inform our conceptualization of reality: A cognitive linguistic investigation. European Journal of Science and Theology. (5)4, 121.

\footnotetext{
i Fairclough refers to 'genre' in terms of the set of "conventions associated with.... socially ratified activity type" (p. 126). 'Discourse', in this particular plane, is the "context, the ideational meaning, subject matter that is represented" (p. 128). 'Style' is linked to particular genres and is understood in terms of its three main parameters of variation: 'mode' (written, spoken, visual or a combination of them); 'tenor' (variation in the level of formality involved in the relationship between participants in the interaction) and 'rhetorical mode' (argumentative, descriptive, etc.).

ii The attitude system within the appraisal framework offers further subcategories for analysis which go beyond the remits of this paper. For a full account of the appraisal system and its theoretical underpinning within Systemic Functional Linguistics see Martin and White (2005).

iii Copyright and printing permission regulations also dictated that the adverts could not be included in this paper.

${ }^{\text {iv }}$ Calendar Girls is a British-American movie filmed in Yorkshire in 2003. The film features a group of women pose nude for a calendar in order to raise funds for a local hospital. The film features well-known British female actors.

'Aristotle's elements of drama are: play structure, character, language and scenography (Barranger, 2004).

${ }^{v i}$ Definition of 'drama' from Collins English Dictionary - Complete and Unabridged: HarperCollins Publishers, 2003, $4^{\text {th }}$ edition.

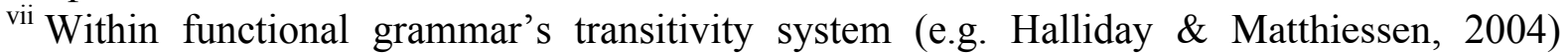
process refers to a semantic verb (e.g. feeling, sensing) and its expression of state of affairs
} 
(i.e. mental state of cognition, perception or affection, in the case of mental processes). Halliday sees such processes as the linguistic products of our perception of the world.

viii Within functional grammar's transitivity system existential processes refer to verb types that indicating that "that something exists or happens" (Halliday \& Matthiessen, 2004, p. 256). 